\title{
Kolaborasi Zoom dengan WAG Sebagai Potret Merdeka Belajar pada Masa New Normal di SMK Negeri 4 Gowa
}

\author{
Zaenab \\ SMK Negeri 4 Gowa, Kabupaten Gowa Provinsi Sulawesi Selatan \\ Corresponding Author. Email: enabesemka@gmail.com
}

\begin{abstract}
This study aimed to describing the portrait of freedom of learning through Zoom collaboration with the WA Group in the New Normal era in class $\mathrm{X}$ TKJ 1 SMKN 4 Gowa. This research method used descriptive methods with a qualitative approach. The subjects of this study were students totaling 35 people. The research instrument used observation, tests, and questionnaires. Meanwhile, the data analysis technique used in this research was descriptive analysis. The results of this study indicate that the motivation and learning activities of class X TKJ 1 SMKN 4 Gowa students during the new Normal period with the learning process through the collaboration of Zoom with the WA Group are in a positive tendency with a percentage agreeing $41.5 \%$ and those who quite agree $42.0 \%$. From this data it can be concluded that Zoom's collaboration with the WA Group as a portrait of independent learning is the best solution as an alternative method of learning during the Covid-19 pandemic.
\end{abstract}

Abstrak: Penelitian ini bertujuan untuk mendeskripsikan potret merdeka belajar melalui kolaborasi Zoom dengan WA Group di masa New Normal pada kelas X TKJ 1 SMKN 4 Gowa. Metode penelitian ini menggunakan metode deskripitf dengan pendekatan kualitatif. Subyek penelitian ini adalah siswa yang berjumlah 35 orang. Instrumen penelitian ini menggunakan observasi, tes, dan angket. Sedangkan teknik analisis data penelitian ini menggunakan analisis deskritpif. Hasil penelitian ini menunjukkan bahwa motivasi dan aktivitas belajar siswa kelas X TKJ 1 SMKN 4 Gowa selama masa new Normal dengan proses pembelajaran melalui kolaborasi Zoom dengan WA Group berada dalam kecenderungan positif dengan presentase yang menyatakan setuju 41,5\% dan yang cukup setuju 42,0\%. Dari data ini dapat disimpulkan bahwa kolaborasi Zoom denga WA Group sebagai potret merdeka belajar merupakan solusi terbaik sebagai meode alternatif pembelajaran dimasa pandemi Covid-19.

\section{Article History}

Received: $13-11-2020$

Revised: 05-12-2020

Published: 07-01-2021

Key Words:

Freedom of Learning, Covid-19 Pandemic, WA Group, Zoom.

\section{Sejarah Artikel}

Diterima: 13-11-2020

Direvisi: 05-12-2020

Diterbitkan: 07-01-2021

\author{
Kata Kunci: \\ Merdeka Belajar, \\ Pandemi Covid-19, WA \\ Group, Zoom.
}

How to Cite: Zaenab, Z. (2021). Kolaborasi Zoom dengan WAG Sebagai Potret Merdeka Belajar pada Masa New Normal di SMK Negeri 4 Gowa. Jurnal Paedagogy, 8(1). doi:https://doi.org/10.33394/jp.v8i1.3129

\section{Pendahuluan}

Terobosan kebijakan pendidikan baru yang disebut dengan "Merdeka Belajar" telah digulirkan pada akhir tahun 2019. Merdeka belajar bertujuan untuk memberikan keleluasaan para pendidik dan peserta didik dalam melaksanakan kegiatan pembelajaran tentunya harus disertai dengan keinginan masing masing pelaku pendidikan untuk meningkatkan kompetensinya. Internet of things yang berkembang di era industri 4.0 telah merambah di berbagai bidang kehidupan masyarakat, salah satunya yaitu di bidang pendidikan (Lestiyani, 2020).

Di masa pandemi Covid-19 yang berimbas pada kegiatan pendidikan mulai dari jenjang TK sampai dengan Perguruan Tinggi. Pembelajaran daringlah yang dipilih selama pandemi Covid-19, meskipun banyak tantangan yang dihadapi oleh peserta didik, guru dan orang tua seperti kesiapan sarana dan prasarana, tidak ada standar untuk hasil pembelajaran, fasilitas pembelajaran seperti konektivitas internet dan peralatan komunikasi seperti laptop 
dan smartphone yang tidak dimiliki oleh semua peserta didik. Pembelajaran di kelas diganti menjadi Belajar dari rumah (BDR). Model pembelajaran tatap muka menjadi tatap layar. Namun, pelaksanaannya tak semudah apa yang kita bayangkan. Di karenakan ketersediaan internet dan infrastruktur teknologi yang merupakan keharusan selama pembelajaran di masa Pandemi Covid-19. Adanya beberapa area yang memiliki keterbatasan aksesbilitas seperti konektivitas internet yang ini menjadi tantangan dalam kegiatan pembelajaran.

Belajar dari Rumah (BDR) dilaksanakan dengan sistem Pembelajaran Jarak Jauh (PJJ). Dalam Undang-undang No. 20 tahun 2003 pasal 1 ayat 15, dijelaskan bahwa PJJ adalah pendidikan yang peserta didiknya terpisah dari pendidik dan pembelajarannya menggunakan berbagai sumber belajar melalui teknologi komunikasi, informasi dan media lain. Dalam pelaksanaannya, PJJ dibagi menjadi dua pendekatan, yaitu pembelajaran jarak jauh dalam jaringan (daring) dan pembelajaran jarak jauh luar jaringan (luring). Dalam pelaksanaan PJJ, satuan pendidikan dapat memilih pendekatan (daring atau luring atau kombinasi keduanya) sesuai dengan karakteristik dan ketersediaan, kesiapan sarana dan prasarana (Asmuni, 2020; Ahmad, 2020, Nurhayati, 2020).

Pembelajaran Kimia yang sebaiknya dilaksanakan di laboratorium menjadi sebuah tantangan yang ditemukan di lapangan. Tentu saja yang paling utama adalah sarana pembelajaran jarak jauh yang dikenal dengan daring (dalam jaringan). Agar proses pembelajaran Kimia dapat terlaksana dengan baik dan membangun proses komunikasi yang efektif, salah satu aplikasi yang bisa di download melalui playstore atau laptop, yakni Zoom dan $W A G$.

Berdasarkan masalah tersebut, perlu dilakukan pembenahan dalam proses pembelajaran di masa pandemi Covid-19 melalui tindakan model yang tepat dan dapat digunakan dalam pembelajaran Kimia dengan daring. Disamping itu juga guru harus melakukan variasi dalam menyampaikan informasi pembelajaran kepada peserta didik sehingga peserta jadi termotivasi dan aktif dalam mengikuti kegiatan pembelajaran secara daring (Sadikin \& Hamidah, 2020; Susmiati, 2020). Dalam pengembangannya, saat ini sudah banyak bermunculan aplikasi-aplikasi yang khusus digunakan sebagai media untuk melakukan pendidikan atau pembelajaran jarak jauh dua di antaranya yakni dengan menggunakan Whatsapp Group dan Pembelajaran Tatap Muka Zoom (Kusuma \& Hamidah, 2020; Daniati, 2020). Kolaborasi antara Zoom dengan WAG merupakan suatu alternatif terbaik yang digunakan dalam kegiatan pembelajaran daring, karena lebih efektif dalam melakukan diskusi atau pembahasan materi dengan komunikasi yang didukung dengan fiturfitur yang terdapat dalam Zoom dan WAG. (Brahma, 2020; Kusuma \& Hamidah, 2020; Yulianto et al., 2020; Najafi \& Tridane, 2015). Hal tersebut menggambarkan bahwa pembelajaran daring dengan menggunakan platform yang dapat diakses oleh semua peserta didik karena hemat kuota dan dikenal dengan baik oleh peserta didik. Adapun tujuan penelitian ini adalah untuk mendeskripsikan potret merdeka belajar melalui kolaborasi Zoom dengan WA Group di masa New Normal pada kelas X TKJ 1 SMK Negeri 4 Gowa.

\section{Metode Penelitian}

Metode penelitian ini menggunakan penelitian deskriptif kualitatif yaitu menggambarkan peristiwa yang terjadi saat melakukan kegiatan pembelajaran daring. Subyek dalam penelitian ini adalah kelas X TKJ1 sebanyak 35 orang. Pelaksanaan kegiatan daring dilakukan 2 kali pertemuan atau 6 jam pelajaran dengan alokasi waktu 6 x 30 menit (selama 2 minggu) secara daring melalui Zoom dan pengiriman tugas-tugas mandiri melalui Whatshapp Group (WAG) kelas yang meliputi : 
Tahap Perencanaan

1) Menyampaikan jadwal pembelajaran kepada siswa melalui Whatsapp Group (WAG) kelas.

2) Menyampaikan informasi kepada peserta didik tentang materi yang akan dibahas melalui Whatsapp Group (WAG) kelas.

3) Menyampaikan kepada peserta didik untuk mendownload aplikasi Zoom di android atau laptop melalui informasi di Whatsapp Group (WAG) kelas.

4) Guru sebagai penulis membuat rencana persiapan pembelajaran untuk dua kali pertemuan dan tugas mandiri siswa termasuk daftar nilai keaktifan.

5) Menyiapkan bahan tayang berupa penguatan materi ajar

6) Menyediakan lembar instrumen berupa kuisioner angket evaluasi pembelajaran melalui google form.

Tahap Pelaksanaan Kegiatan

1) Menyajikan materi sesuai kompetensi dasar untuk memecahkan masalah yang mengarah pada pemecahan masalah secara aktif melalui aplikasi Zoom dan Whatsapp Group (WAG).

2) Selama proses pembelajaran berlangsung guru memberikan bimbingan dan umpan balik pada siswa melalui kegiatan eksplorasi dengan mengacu pada RPP

Tahap Observasi secara formal sebagai potret merdeka belajar.

Pada tahap ini dilaksanakan saat pemberian tindakan yakni :

a) Observasi yang dilakukan guru berdasarkan keaktifan siswa selama melakukan diskusi. Semua kejadian dicatat oleh guru sebagai penulis dengan format observasi yang telah disusun.

b) Hal-hal yang menjadi perhatian guru sebagai penulis dalam tahap ini adalah keaktifan siswa selama proses belajar berlangsung antara lain siswa yang hadir pada saat pembelajaran, siswa yang memberikan jawaban sementara ketika diberikan masalah di awal pembelajaran,siswa yang memperhatikan materi yang diajarkan guru.

c) Guru sebagai penulis memberikan penguatan materi di akhir pertemuan.

d) Guru memberikan tugas mandiri yang dikirim melalui Whatsapp Group (WAG) selanjutnya siswa mengirimkan jawaban masing-masing melalui email guru untuk memperoleh umpan balik.

Seperti yang dijelaskan sebelumnya, bahwa aplikasi yang digunakan adalah Zoom dengan mengirimkan link melalui Whatsapp Group (WAG) kelas. Sedangkan instrumen yang digunakan adalah :

a) Instrumen untuk mengamati proses pembelajaran

b) Instrumen tes kemampuan kognitif berupa soal-soal sederhana untuk didiskusikan selama pembelajaran berlangsung.

c) Instrumen kousioner tentang evaluasi pembelajaran selama masa pandemi Covid-19

Adapun teknik analisis data yang digunakan dalam penelitian ini adalah analisis deskriptif kualitatif dan kuantitatif. 


\section{Hasil Penelitian dan Pembahasan}

Dari hasil penelitian yang dilakukan pada siswa kelas X TKJ 1 dengan pengisian kousioner evaluasi pelaksanaan pembelajaran di New Normal tahun pelajaran 2020/2021 dapat diuraikan sebagai berikut :

1) Proses pembelajaran melalui kolaborasi Zoom dan Whatshapp Group di masa New Normal pada kelas X TKJ 1 menunjukkan siswa menjadi lebih aktif merespon pertanyaan dari guru termasuk mengajukan pertanyaan pada guru maupun sesama teman siswa.

2) Proses pembelajaran melalui kolaborasi Zoom dan Whatshapp Group di masa New Normal pada kelas X TKJ 1 dengan berdasarkan hasil pengisian kuesioner evaluasi selama pembelajaran melalui link google form yang dibuat penulis dapat dilihat pada tabel berikut :

Tabel 1. Presentase Hasil Pengisian Kousioner Evaluasi Pelaksanaan Pembelajaran Kimia pada masa New Normal Kelas X TKJ 1 SMKN 4 Gowa Tahun Pelajaran 2020/2021.

\begin{tabular}{|c|l|c|c|c|c|}
\hline \multirow{2}{*}{ Pernyataan Kousioner } & \multicolumn{1}{|c|}{ Persentase (\% ) } \\
\cline { 3 - 6 } & \multicolumn{1}{|c|}{1} & 2 & 3 & 4 \\
\hline 2 & $\begin{array}{l}\text { Aplikasi Model Pembelajaran Zoom dengan } \\
\text { WA Group mudah dilakukan oleh siswa }\end{array}$ & 1,3 & 5,2 & 41,6 & 51,9 \\
\hline 3 & $\begin{array}{l}\text { Aplikasi Model Pembelajaran Zoom dengan } \\
\text { WA Group menarik bagi siswa }\end{array}$ & 3,9 & 18,2 & 36.4 & 41,6 \\
\hline 4 & $\begin{array}{l}\text { Aplikasi Model Pembelajaran Zoom dengan } \\
\text { WA Group menambah pengetahuan siswa } \\
\text { dalam pemanfaatan teknologi }\end{array}$ & 1,3 & 11,7 & 46,8 & 40,3 \\
\hline 5 & $\begin{array}{l}\text { Aplikasi Model Pembelajaran Zoom dengan } \\
\text { WA Group memotivasi siswa }\end{array}$ & 3,8 & 17,9 & 42,3 & 35,9 \\
\hline $\begin{array}{l}\text { Aplikasi Model Pembelajaran Zoom dengan } \\
\text { WA Group membuat aktif siswa sebagai } \\
\text { bagian merdeka belajar. }\end{array}$ & 1,3 & 18,2 & 42,9 & 37,7 \\
\hline Rata-rata Presentase (\%) & 2,3 & 14,2 & 42,0 & 41,5 \\
\hline
\end{tabular}

Keterangan : 1= tidak setuju 2= kurang setuju 3 = cukup setuju $4=$ setuju

Tabel 2. Model Diagram Lingkaran yang diperoleh dari hasil Google Form tentang Evaluasi Pelaksanaan Pembelajaran Kimia pada masa New Normal Kelas X TKJ 1

\begin{tabular}{|l|l|l|l|l|l|}
\hline No & $\begin{array}{l}\text { Pernyataan } \\
\text { Kousioner 1 }\end{array}$ & $\begin{array}{l}\text { Pernyataan } \\
\text { Kousioner 2 }\end{array}$ & $\begin{array}{l}\text { Pernyataan } \\
\text { Kousioner 3 }\end{array}$ & $\begin{array}{l}\text { Pernyataan } \\
\text { Kousioner 4 }\end{array}$ & $\begin{array}{l}\text { Pernyataan } \\
\text { Kousioner 5 }\end{array}$ \\
\hline & & & &
\end{tabular}


Keterangan $: 1$ Biru $=$ Tidak Setuju 2. Coklat $=$ Kurang Setuju 3. Orange $=$ Cukup Setuju 4. Hijau = Setuju

Berdasarkan tabel 1 dan tabel 2 diatas memberikan gambaran bahwa motivasi dan aktivitas belajar siswa kelas X TKJ 1 SMKN 4 Gowa selama masa new Normal dengan proses pembelajaran melalui kolaborasi Zoom dengan WA Group berada dalam kecenderungan positif dengan presentase yang menyatakan setuju 41,5\% dan yang cukup setuju $42,0 \%$, ini seimbang antara setuju dan cukup setuju sehingga proses pembelajaran Kimia dimasa New Normal berjalan lancar sesuai yang ditampilkan dalam diagram lingkaran dengan warna hijau dan orange.

Dalam pertemuan perdana pada pembelajaran kimia ada tiga orang siswa yang tidak berpartisipasi aktif secara daring dikarenakan tidak memahami cara penggunaan aplikasi Zoom. Namun dengan sigap diatasi dengan mensimulasikan ulang cara penggunaan aplikasi Zoom dalam pembelajaran sehingga siswa tersebut dapat ikut serta dalam pembelajaran Kimia. Disamping itu juga terdapat beberapa siswa yang tidak sempat mengikuti pemaparan materi pembelajaran Kimia dalam bentuk diskusi secara maksimal karena jaringan internet mereka kurang baik dan juga tidak memiliki kouta internet. Dalam hal ini untuk hal tersebut, dikirimkan video rekaman dari penjelasan materi di Zoom melalui WA Group agar mereka dapat mempelajari dan memahaminya.

\section{Kesimpulan}

Kesimpulan yang diperoleh dari hasil penelitian ini bahwa pembelajaran daring yang dilaksanakan selama pandemi covid-19 dengan kolaborasi Zoom dan WA Group sebagai potret merdeka belajar di masa New Normal pada kelas X TKJ 1 SMKN 4 Gowa Tahun Pelajaran 2020/2021 berjalan cukup lancar sebagai salah satu media alternatif pembelajaran pengganti pembelajaran tatap muka secara langsung di kelas sekaligus memberikan gambaran tentang potret merdeka belajar sebagai suatu inovasi dan kreatifitas metode pembelajaran yang dirancang penulis agar tujuan pembelajaran dapat tercapai di masa pandemi Covid-19.

\section{Saran}

Saran yang dapat disampaikan berdasarkan hasil penelitian ini adalah agar guru atau pendidik lainnya dapat mengaplikasikan kolaborasi Zoom dan WA Group ini sebagai potret merdeka belajar di masa New Normal ini, tentu dengan meningkatkan kualitas materi pelajaran dengan memanfaatkan berbagai sumber yang ada.

\section{Daftar Pustaka}

Ahmad, A. (2020). Peningkatan Kompetensi Pedagogik Guru dalam Pembelajaran Jarak Jauh Melalui Pendampingan Sistem Daring, Luring, atau Kombinasi pada Masa New Normal Covid-19. Jurnal Paedagogy, $\quad 7(4), \quad 258-264$. doi:https://doi.org/10.33394/jp.v7i4.2803

Asmuni, A. (2020). Problematika Pembelajaran Daring di Masa Pandemi Covid-19 dan Solusi Pemecahannya. Jurnal Paedagogy, 7(4), 281-288. doi:https://doi.org/10.33394/jp.v7i4.2941

Brahma, I. A. (2020). Penggunaan Zoom Sebagai Pembelajaran Berbasis Online Dalam Mata Kuliah Sosiologi dan Antropologi Pada Mahasiswa PPKN di STKIP Kusumanegara Jakarta. Aksara: Jurnal Ilmu Pendidikan Nonformal, 6(2), 97. https://doi.org/10.37905/aksara.6.2.97-102.2020 
Chaidar, H. (2014). Pemanfaatan Teknologi Informasi dan Komunikasi dalam Pembelajaran di SMA Muhammadiyah Tarakan. Jurnal Kebijakan Dan Pengembangan Pendidikan, 2(2), 184-192.

Daniati, D., Ismanto, B., \& Luhsasi, D. (2020). Upaya Peningkatan Motivasi dan Hasil Belajar Mahasiswa dengan Penerapan Model Pembelajaran E-Learning Berbasis Google Classroom pada Masa Pandemi Covid-19. Jurnal Kependidikan: Jurnal Hasil Penelitian dan Kajian Kepustakaan di Bidang Pendidikan, Pengajaran dan Pembelajaran, 6(3), 601-608. doi:https://doi.org/10.33394/jk.v6i3.2642

Firman, F., \& Rahayu, S. (2020). Pembelajaran Online di Tengah Pandemi Covid-19. Indonesian Journal of Educational Science (IJES), 2(2), 81-89. https://doi.org/10.31605/ijes.v2i2.659

Hikmat, Hermawan, E., Aldim, \& Irwandi. (2020). Efektivitas Pembalajaran Daring Selama Masa Pandemi Covid-19: Sebuah Survey Online. Digital Library, UIN SUnan Gung Djati, Bandung, 1-7. http://digilib.uinsgd.ac.id/30625/

Kusuma, J. W., \& Hamidah, H. (2020). Perbandingan Hasil Belajar Matematika Dengan Penggunaan Platform Whatsapp Group Dan Webinar Zoom Dalam Pembelajaran Jarak Jauh Pada Masa Pandemik Covid 19. JIPMat, 5(1). https://doi.org/10.26877/jipmat.v5i1.5942

Lestiyani, P. (2020). Analisis Persepsi Civitas Akademika Terhadap Konsep Merdeka Belajar Menyongsong Era Industri 5.0. Jurnal Kependidikan: Jurnal Hasil Penelitian dan Kajian Kepustakaan di Bidang Pendidikan, Pengajaran dan Pembelajaran, 6(3), 365372. doi:https://doi.org/10.33394/jk.v6i3.2913

Muin, A. (2020). Dampak Corona, Siswa di Makassar Belajar Online dari Rumah. In IDN Times Sulsel.

Nurhayati, E. (2020). Meningkatkan Keaktifan Siswa Dalam Pembelajaran Daring Melalui Media Game Edukasi Quiziz pada Masa Pencegahan Penyebaran Covid-19. Jurnal Paedagogy, 7(3), 145-150. doi:https://doi.org/10.33394/jp.v7i3.2645

Pakpahan, R., \& Fitriani, Y. (2020). JISAMAR (Journal of Information System, Applied, Management, Accounting and Researh). 4(2), 30-36.

Perencanaan, K., Nasional, P., Republik, B., Abstraksi, I., Baru, N., Pembangunan, R., Menengah, J., Kunci, K., Journal, T. I., Planning, D., \& Iv, V. (2020). Covid-19, New Normal, dan Perencanaan Pembangunan di Indonesia. Jurnal Perencanaan Pembangunan: The Indonesian Journal of Development Planning, 4(2), 240-252. https://doi.org/10.36574/jpp.v4i2.118

Puspitorini, F. (2020). Strategi Pembelajaran Di Perguruan Tinggi Pada Masa Pandemi Covid-19. Jurnal Kajian Ilmiah, 1(1), 99-106. https://doi.org/10.31599/jki.v1i1.274

Riyana, C. (2013). Produksi Bahan Pembelajaran Berbasis Online. Modul Pembelajaran Universitas Terbuka Tangerang Selatan, 1-43.

Sadikin, A., \& Hamidah, A. (2020). Pembelajaran Daring di Tengah Wabah Covid-19. Biodik, 6(2), 109-119. https://doi.org/10.22437/bio.v6i2.9759

Sumira, D. Z., Deasyanti, D., \& Herawati, T. (2018). Pengaruh Metode Scramble dan Minat Baca terhadap Kemampuan Membaca Pemahaman Siswa Sekolah Dasar. Indonesian Journal of Primary Education, 2(1), 62. https://doi.org/10.17509/ijpe.v2i1.11673

Suni Astini, N. K. (2020). Tantangan Dan Peluang Pemanfaatan Teknologi Informasi Dalam Pembelajaran Online Masa Covid-19. Cetta: Jurnal Ilmu Pendidikan, 3(2), 241-255. https://doi.org/10.37329/cetta.v3i2.452 
Susmiati, E. (2020). Meningkatkan Motivasi Belajar Bahasa Indonesia Melalui Penerapan Model Discovery Learning dan Media Video Dalam Kondisi Pandemi Covid-19 bagi Siswa SMPN 2 Gangga. Jurnal Paedagogy, 7(3), 210-215. doi:https://doi.org/10.33394/jp.v7i3.2732

Widiyono, A. (2020). Efektifitas Perkuliahan Daring (Online) pada Mahasiswa PGSD di Saat Pandemi Covid 19 Aan Widiyono. Jurnal Pendidikan, 8(2), 169-177.

Yulianto, E., Cahyani, P. D., \& Silvianita, S. (2020). Perbandingan Kehadiran Sosial dalam Pembelajaran Daring Menggunakan Whatsapp group dan Webinar Zoom Berdasarkan Sudut Pandang Pembelajar Pada Masa Pandemic COVID-19. 3(2), 331-341. http://journal-litbang- rekarta.co.id/index.php/jartika/article/view/277 